\title{
Intestinal absorption of forsythoside A in in situ single-pass intestinal perfusion and in vitro Caco-2 cell models
}

\author{
Wei ZHOU ${ }^{1}$, Liu-qing $\mathrm{DI}^{1, *}$, Juan WANG ${ }^{1}$, Jin-jun SHAN ${ }^{1}$, Shi-jia LIU², Wen-zheng JU², Bao-chang CAI ${ }^{1}$ \\ ${ }^{1}$ College of Pharmacy, Nanjing University of Chinese Medicine, Nanjing 210046, China; ${ }^{2}$ Department of Clinical Pharmacology, Affili- \\ ated Hospital of Nanjing University of Chinese Medicine, Nanjing 210093, China
}

\begin{abstract}
Aim: To investigate the mechanisms underlying the intestinal absorption of the major bioactive component forsythoside A (FTA) extracted from Forsythiae fructus.

Methods: An in vitro Caco-2 cell model and a single-pass intestinal perfusion in situ model in SD rats were used.

Results: In the in vitro Caco- 2 cell model, the mean apparent permeability value $\left(P_{\text {app }}\right.$-value) was $4.15 \times 10^{-7} \mathrm{~cm} / \mathrm{s}$ in the apical-tobasolateral (AP-BL) direction. At the concentrations of 2.6-10.4 $\mathrm{gg} / \mathrm{mL}$, the efflux ratio of FTA in the bi-directional transport experiments was approximately 1.00. After the transport, $>96 \%$ of the apically loaded FTA was retained on the apical side, while $>97 \%$ of the basolaterally loaded FTA was retained on the basolateral side. The $P_{\text {app }}$-values of FTA were inversely correlated with the transepithelial electrical resistance. The paracellular permeability enhancers sodium caprate and EDTA, the P-gp inhibitor verapamil and the multidrug resistance related protein (MRP) inhibitors cyclosporine and MK571 could concentration-dependently increase the Papp-values, while the uptake (OATP) transporter inhibitors diclofenac sodium and indomethacin could concentration-dependently decrease the $P_{\text {app }}$-values. The intake transporter SGLT1 inhibitor mannitol did not cause significant change in the $P_{\text {app }}$-values. In the in situ intestinal perfusion model, both the absorption rate constant $\left(K_{\mathrm{a}}\right)$ and the effective permeability ( $P_{\text {eff }}$-values) following perfusion of FTA 2.6, 5.2, and $10.4 \mu \mathrm{g} / \mathrm{mL}$ via the duodenum, jejunum and ileum had no significant difference, although the values were slightly higher for the duodenum as compared to those in the jejunum and ileum. The low, medium and high concentrations of verapamil caused the largest increase in the $P_{\text {eff }}$ values for duodenum, jejunum and ileum, respectively. Sodium caprate, EDTA and cyclosporine resulted in concentration-dependent increase in the $P_{\text {eff }}$ values. Diclofenac sodium and indomethacin caused concentration-dependent decrease in the Peff-values. Mannitol did not cause significant change in the $P_{\text {app }}$-values for the duodenum, jejunum or ileum.

Conclusion: The results suggest that the intestinal absorption of FTA may occur through passive diffusion, and the predominant absorption site may be in the upper part of small intestine. Paracellular transport route is also involved. P-gp, MRPs and OATP may participate in the absorption of FTA in the intestine. The low permeability of FTA contributes to its low oral bioavailability.
\end{abstract}

Keywords: forsythoside A; in situ intestinal perfusion; Caco-2 cells; intestinal absorption; pharmacokinetics; P-gp; multidrug resistance related protein; uptake (OATP) transporter

Acta Pharmacologica Sinica (2012) 33: 1069-1079; doi: 10.1038/aps.2012.58; published online 9 Jul 2012

\begin{abstract}
Introduction
Intestinal absorption evaluated using an in vitro Caco- 2 model and a single-pass intestinal perfusion in situ model has become increasingly important in pharmaceutical designation ${ }^{[1,2]}$. The human colon adenocarcinoma cell line (Caco-2) is now routinely cultivated as monolayers on permeable filters for the transepithelial transport of drugs ${ }^{[3]}$, and this model has been used extensively to screen the absorptive capability and capac-
\end{abstract}

\footnotetext{
* To whom correspondence should be addressed.

E-mail diliuqing@yahoo.com.cn

Received 2011-11-16 Accepted 2012-04-28
}

ity of a variety of nutrients and pharmaceuticals ${ }^{[4-6]}$. However, one of the functional differences between normal cells and Caco-2 cells is the lack of expression of the cytochrome P450 isoenzymes, particularly CYP3A4, as well as some uridine diphosphate-glucuronosyltransferases (UGTs), such as $\mathrm{UGT1A} 1^{[7]}$. In summary, Caco-2 cells do not always express the appropriate amounts of transporters or enzymes, which may introduce bias in the determination of some drug candidates that are transported via a carrier-mediated process or are metabolised via a particular pathway. Compared to the Caco-2 monolayer model, in situ intestinal perfusion in rats is a more reliable technique for investigating drug absorp- 
tion potential in combination with intestinal metabolism ${ }^{[8]}$. However, it is time consuming, and therefore is not normally recommended for screening purposes. Due to the advantages and disadvantages of each of these models, most of the published reports investigate the intestinal absorption of drugs using both models simultaneously. For example, Zuo et al, 2006 ${ }^{[9]}$ studied the intestinal absorption of hawthorn flavonoids using Caco-2 cells and in situ intestinal perfusion and found that hyperoside (HP), isoquercitrin (IQ) and epicatechin (EC) had quite limited permeability. EC and IQ demonstrated more extensive metabolism in the rat in situ intestinal perfusion model than in the Caco-2 monolayer model.

Forsythoside A (FTA), the major active component of the extracts from Forsythiae fructus ${ }^{[10]}$, is present in traditional Chinese medicinal preparations such as Shuang-Huang-Lian or the Forsythiae fructus-Lonicerae japonicae flos herb couple, which possesses strong antibacterial, antioxidant and antiviral activities ${ }^{[1]}$. However, its oral bioavailability (BA) in rats was low $(0.5 \%)^{[12]}$. Surprisingly, until recently, the absorption mechanism of FTA was completely unknown. In a previous study, Lu et al, 2010 ${ }^{[13]}$ found that the oral BA of the FTA oily formulation was fivefold higher than that of the non-oily formulation, but the reason for this difference was not studied. Zhang et al, 2002 ${ }^{[11]}$ conducted a physicochemical study of FTA, showing it to be a highly hydrophilic compound that was almost completely dissociated in biological fluids. This physicochemical property of the drug led us to postulate that the low permeability of the drug in the intestinal mucosa was one important reason for its reported low bioavailability. The Food and Drug Administration (FDA) also recognises that the poor permeation of drugs across the intestinal mucosa (usually due to their high hydrophilicity) was one of the common factors leading to failed absorption and thus to low drug $\mathrm{BA}^{[14]}$. Whether the improvement of the lipid solubility of FTA can increase its oral BA and whether other influencing factors such as efflux transporters, P-glycoprotein (P-gp), multidrug resistance related proteins (MRPs) also decrease the bioavailability of FTA are yet to be investigated.

Therefore, verapamil (VER), a P-gp inhibitor ${ }^{[15]}$; cyclosporine (CSA) and MK571, MRP inhibitors ${ }^{[16]}$; mannitol (MAN), a SGLT1 inhibitor ${ }^{[17,18]}$; diclofenac sodium (DFS) and indomethacin (INDO), OATP inhibitors ${ }^{[19,20]}$ and sodium caprate and EDTA, paracellular permeability enhancers (PPEs) ${ }^{[21,22]}$ were selected to study the absorption mechanism and the factors that influence the intestinal absorption of FTA using an in vitro Caco-2 model and an in situ intestinal perfusion model to elucidate why the oral BA of FTA was low and to identify suitable pharmaceutical methods to improve the BA of FTA.

\section{Materials and methods \\ Materials}

FTA (98\% purity, structure shown in Figure 1) was purchased from Shanghai NatureStandard Biotech Co, Ltd. Chlorogenic acid (CHA) (used as an internal standard, IS), VER, CSA, mannitol, DFS and INDO were purchased from the National Institute for the Control of Pharmaceutical and Biological Prod- ucts. MK571, EDTA, sodium caprate, Lucifer yellow (LY) and DMSO were purchased from Sigma Chemical Co (St Louis, MO, USA). Methanol and acetonitrile (HPLC grade) were purchased from Merck (Merck, Germany), and water was purified using a Milli-Q water purification system (Millipore, Bedford, MA, USA). All other chemicals and reagents were of analytical grade.

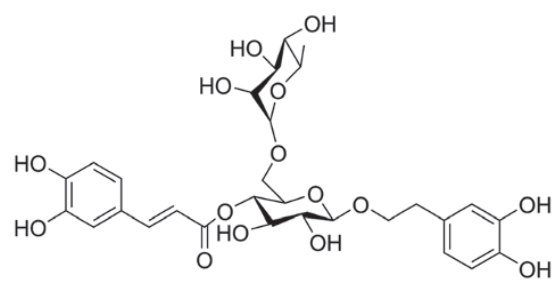

Figure 1. Chemical structure of forsythoside A (FTA).

\section{In vitro Caco-2 cell model}

Preparation of the calibration standard and quality control (QC) samples

Stock solutions of IS and FTA with concentrations of 10.28 and $26 \mu \mathrm{g} / \mathrm{mL}$ were prepared in Hanks' Balanced Salt Solution (HBSS) with a $\mathrm{pH} 6.0^{[23]}$ and stored at $-20^{\circ} \mathrm{C}$ away from light. The working solutions used for HBSS were all freshly prepared by diluting the stock solution with HBSS to the appropriate concentrations.

The calibration standard samples were prepared in HBSS at concentrations of $5.28-264 \mathrm{ng} / \mathrm{mL}$ for FTA and processed as described in the sample preparation. The QC samples used for the intra-day and inter-day accuracy and precision, extraction recovery and stability study were prepared in the same way as the calibration standard samples.

\section{Cell culture}

Caco- 2 cells obtained from the Chinese Academy of Medical Sciences were cultured in high glucose Dulbecco's modified Eagle's medium (DMEM, Gibco, Bethesda, MD, USA) with $10 \%$ fetal bovine serum (Gibco) and 1\% nonessential amino acids (Gibco). Cells were cultured in a humidified atmosphere of $5 \% \mathrm{CO}_{2}$ at $37^{\circ} \mathrm{C}$. After reaching $80 \%$ confluence, the Caco- 2 cells were harvested with a $0.25 \%$ trypsin-EDTA solution and seeded in Transwell inserts (Corning Coster Corp, Action, MA, USA) in 12-well plates at a density of $1.0 \times 10^{5}$ cells $/ \mathrm{cm}^{2}$. The protocols for cell culture in the Transwell inserts were similar to those described previously.

\section{FTA transport experiments}

Caco-2 cells at passages of 50-55 were used for transport experiments after 21 days post seeding. The integrity of the monolayer was verified by measuring the transepithelial electrical resistance (TEER) value across the monolayer using a Millicell-ERS Volt-Ohm meter (Millipore, Billerica, MA, USA) and monitoring the permeability of the paracellular leakage marker LY across the monolayer. The cell monolayer was con- 
sidered tight enough for transport experiments when the $P_{\text {app }}$ for $\mathrm{LY}<0.3 \times 10^{-6} \mathrm{~cm} / \mathrm{s}$ and the TEER value $>350 \Omega / \mathrm{cm}^{2}$. All transport studies were conducted in an orbital shaker incubator at $37^{\circ} \mathrm{C}$ and a constant stirring rate $(50-60 \mathrm{r} / \mathrm{min})$. Prior to the experiment, the cells were washed twice and equilibrated for 30 min with the transport medium, HBSS containing 25 mmol/L of HEPES. The stock solutions of compounds were prepared in DMSO and diluted to the desired final concentration using HBSS. The concentration of DMSO in the final solutions was less than $0.10 \%(v / v)$. The transport studies were conducted in both the absorptive and efflux directions, separately. The transport solutions were added on either the apical $(\mathrm{A}, 0.4 \mathrm{~mL})$ or the basolateral $(\mathrm{B}, 0.6 \mathrm{~mL})$ side of the inserts, while the receiving compartment contained the corresponding volume of blank transport medium. After 30, 60, 90, and 120 min of incubation, aliquots of $200 \mu \mathrm{L}$ or $150 \mu \mathrm{L}$ were withdrawn from the basolateral or the apical receiver chambers, respectively, and replenished with an equal volume of HBSS. The concentrations of the test compound were analysed immediately using the HPLC-MS method described below. The effects of different concentrations, paracellular permeability enhancers (PPEs; EDTA and sodium caprate) and various transporter inhibitors, such as CSA, MK571, VER, mannitol, DFS and INDO, on the absorption of FTA were investigated.

\section{Sample preparation}

Samples were removed from $-80^{\circ} \mathrm{C}$ storage and thawed under ambient conditions. Samples of $100 \mu \mathrm{L}$ were extracted using a liquid-liquid extraction technique after the addition of $10 \mu \mathrm{L}$ of IS solutions, $20 \mu \mathrm{L}$ of $\mathrm{HCl}(1 \mathrm{~mol} / \mathrm{L})$ and $1000 \mu \mathrm{L}$ of ethyl acetate. After vortexing for $120 \mathrm{~s}$ and centrifugation at 12000 $\mathrm{r} / \mathrm{min}$ for $5 \mathrm{~min}$, the organic phase was transferred into a clean centrifuge tube and evaporated to dryness under a nitrogen stream at $25^{\circ} \mathrm{C}$ away from light. The residue was reconstituted in $100 \mu \mathrm{L}$ of methanol aqueous solution containing $20 \%$ water. After centrifugation at $10464 \times g$ for $10 \mathrm{~min}$, the supernatant was injected to the LC-MS system.

\section{Determination of FTA in HBSS}

The chromatographic separation was achieved on an Agilent Zorbax SB-C18 column (2.1 mm id ×150 mm, $5 \mu \mathrm{m}$, Agilent Technologies, Wilmington, DE, USA) with a security guard column $(2.1 \mathrm{~mm}$ id $\times 12.5 \mathrm{~mm}, 5 \mu \mathrm{m}$, Agilent Zorbax SB-C18, DE, USA) and was eluted with an isocratic mobile phase of $\mathrm{MeOH}$ and water (20:80). The mobile phase was delivered at a flow-rate of $0.2 \mathrm{~mL} / \mathrm{min}$, and the column temperature was maintained at $30^{\circ} \mathrm{C}$. An Alliance 2695 LC system (Waters, Milford, MA, USA) coupled with a Waters Quattro Micro tandem triple quadrupole mass spectrometer was used. The Mass Lynx 4.1 software was used for instrumental control and for the acquisition and processing of the data. A MS detector with an electrospray ionisation (ESI) interface in negative ion model (ESI') was used for quantitative analysis, and an MRM model was used for acquisition. The $m / z$ ratios, $[\mathrm{M}-\mathrm{H}]^{-}$, $m / z 623.8 \rightarrow 161.3$ for FTA and [M-H] $]^{-}, m / z 353.3 \rightarrow 191.2$ for IS, were recorded simultaneously. The optimised electrospray conditions were: capillary voltage $-3.0 \mathrm{kV}$; cone voltage - $30 \mathrm{~V}$; source temperature $-110^{\circ} \mathrm{C}$; desolation temperature $-350^{\circ} \mathrm{C}$; desolation gas flow $-500 \mathrm{~L} / \mathrm{h}$. The method was fully validated for its specificity, linearity, lower limits of quantification (LLOQ), accuracy and precision. To evaluate assay specificity, six independent lots of blank Caco-2 receiver solutions were analysed to exclude any endogenous co-eluting interferences by comparing them with the assay of the receiver solutions spiked with analytes. The precision was calculated as the relative standard deviation (RSD), and the accuracy was evaluated as analytical recovery. The intra-day precision and accuracy were evaluated at three different concentrations (5.28, 26.4, and $132 \mathrm{ng} / \mathrm{mL}$ ) of the receiver solutions spiked with analytes by replicate analysis of five samples on the same day. The inter-day precision and accuracy determinations were carried out on three different days. The recovery experiments were performed by comparing the analytical results of the extracted samples at three concentrations with pure standards without extraction. The LLOQ was defined as the concentration that produced a signal-to-noise $(\mathrm{S} / \mathrm{N})$ ratio greater than 10 . The sample solution stability was assessed at three concentration levels $(5.28,26.4$, and $132 \mathrm{ng} / \mathrm{mL})$. For the freeze/thaw stability study, samples at three concentrations were stored at $-20^{\circ} \mathrm{C}$ and subjected to two freeze-thaw cycles. The short-term stability test of FTA during storage in the autosampler at $4{ }^{\circ} \mathrm{C}$ was performed by repeated injections every $2 \mathrm{~h}$ for a period of $24 \mathrm{~h}$. The long-term stability of FTA in HBSS was assessed at three concentration levels after storage at $-20^{\circ} \mathrm{C}$ for 4 weeks.

\section{Data analysis}

The apparent permeability coefficient $\left(P_{\text {app }}\right)$ and efflux ratio were calculated using the following equations:

$$
\begin{aligned}
& P_{\text {app }}=\frac{\mathrm{d} Q}{\mathrm{~d} t} \times \frac{1}{A^{*} C_{0}} \\
& \text { Efflux ratio }=\frac{P_{\text {app }}(B L \rightarrow A P)}{P_{\text {app }}(A P \rightarrow B L)}
\end{aligned}
$$

Notes: $\mathrm{d} Q / \mathrm{d} t(\mu \mathrm{g} / \mathrm{s})$ was the flux rate, $A$ was the effective surface area of the cell monolayer $\left(0.67 \mathrm{~cm}^{2}\right)$, and $C_{0}(\mu \mathrm{g} / \mathrm{mL})$ was the initial drug concentration in the donor chamber. The net efflux was expressed as the quotient of $P_{\text {app }}(\mathrm{B} \rightarrow \mathrm{A})$ to $P_{\text {app }}$ $(\mathrm{A} \rightarrow \mathrm{B})$. The data are expressed as the mean $\pm \mathrm{SD}$ of six determinations (performed on two different days).

The parameters obtained above were compared via an analysis of variance (following logarithmic transformation of the $P_{\text {app }}$ efflux ratio and two-tailed $t$-tests). The differences were considered to be significant when $P<0.05$.

\section{The single-pass intestinal perfusion in situ model Preparation of the perfusion buffer (Krebs-Ringer buffer contain- ing $20 \mathrm{mg} / \mathrm{L}$ of phenol red)}

The perfusion buffer contained $133.3 \mathrm{mmol} / \mathrm{L} \mathrm{NaCl}, 4.7$ $\mathrm{mmol} / \mathrm{L} \mathrm{KCl}, 0.2 \mathrm{mmol} / \mathrm{L} \mathrm{MgCl}$, $3.3 \mathrm{mmol} / \mathrm{L} \mathrm{CaCl}_{2}, 2.7$ $\mathrm{mmol} / \mathrm{L} \mathrm{NaH} \mathrm{PO}_{4}, 7.8 \mathrm{mmol} / \mathrm{L}$ glucose, $16.3 \mathrm{mmol} / \mathrm{L}$ $\mathrm{NaHCO}_{3}$, and $56.4 \mu \mathrm{mol} / \mathrm{L}$ phenol red in $1000 \mathrm{~mL}$ water and was adjusted to $\mathrm{pH} 6.0$ using concentrated phosphoric acid ${ }^{[23]}$. 


\section{Preparation of calibration standard and quality control (QC)} samples

Stock solutions of IS and FTA with concentrations of 508 and $123 \mu \mathrm{g} / \mathrm{mL}$ were prepared in Krebs-Ringer buffer with $\mathrm{pH} 6.0$ and stored at $-20^{\circ} \mathrm{C}$ away from light. The working solutions used for the Krebs-Ringer buffer were all freshly prepared by diluting the stock solution with Krebs-Ringer buffer to the appropriate concentrations.

The calibration standard samples were prepared in KrebsRinger buffer at concentrations of $0.615-12.3 \mu \mathrm{g} / \mathrm{mL}$ for FTA and processed as described for the sample preparation. The QC samples used for the intra-day and inter-day accuracy, precision, extraction recovery and stability study were prepared in the same way as the calibration standard samples.

\section{The in situ uptake experiment}

Male Sprague Dawley (SD) rats weighing $250 \mathrm{~g}$ to $300 \mathrm{~g}$ were supplied by the Experimental Animal Center of Nanjing University of Chinese Medicine (Certificate № SCXK2008-0033). The rats were fasted for $12 \mathrm{~h}$ prior to the experiment but were allowed free access to water. The SD rats were anesthetised with a $20 \%$ urethane solution $(6 \mathrm{mg} / \mathrm{kg})$. A midline abdominal incision was made, and the small intestine was exposed. The bile duct was ligated to avoid bile secretion into the perfusate. For the regional absorption of FTA, three intestinal sections were isolated and cannulated (all were $10 \mathrm{~cm}$ long): the duodenum, the jejunum and the ileum. Each segment was rinsed with normal saline at $37^{\circ} \mathrm{C}$ for $20 \mathrm{~min}$ until the wash appeared clear. After that, the FTA perfusion solution was connected to each segment and perfused through each part of the three intestine sections. After $30 \mathrm{~min}$, the circulation rate was $0.2 \mathrm{~mL} / \mathrm{min}$, controlled by a peristaltic pump to pre-balance. The perfusate samples were collected at 30-60, 60-90, 90-120, and 120-150 min. A $0.5 \mathrm{~mL}$ sample was taken to determine the concentration of phenol red, and the remaining samples were stored at $-80^{\circ} \mathrm{C}$ until analysis following centrifugation at $10464 \times g$ for $5 \mathrm{~min}$. The effects of different concentrations, intestinal sections, PPEs (EDTA and sodium caprate) and various transporter inhibitors, including CSA, VER, mannitol, DFS and INDO, on the absorption of FTA were investigated.

\section{Sample preparation}

Samples were removed from $-80^{\circ} \mathrm{C}$ storage and thawed under ambient conditions. Samples $(100 \mu \mathrm{L})$ were extracted using a protein precipitation technique after the addition of $5 \mu \mathrm{L}$ of IS solution, $10 \mu \mathrm{L} \mathrm{HCl}\left(10^{-3} \mathrm{~mol} / \mathrm{L}\right)$ and $90 \mu \mathrm{L}$ of methanol. After vortexing for $120 \mathrm{~s}$ and centrifugation at $10464 \times g$ for $5 \mathrm{~min}$, the supernatant was injected into the HPLC system.

\section{Determination of phenol red}

The phenol red in the phosphate buffer ( $\mathrm{pH}$ 6.0) had a characteristic red colour, which was measured spectrophotometrically at $558 \mathrm{~nm}$.

\section{Determination of FTA in the intestinal perfusion fluid}

The analyses were performed using an Agilent 1100 liquid chromatography system equipped with a quaternary solvent delivery system, an autosampler and a DAD detector. The separation was carried out on a Hedera ODS-2 column (250 $\mathrm{mm} \times 4.6 \mathrm{~mm}, 5 \mu \mathrm{m})$. The mobile phase consisted of solvent A (0.2\% Phosphate) and solvent B (methanol). The gradient elution was as follows: initial 0-7 min, linear change from A-B $(67: 33, v / v)$ to $\mathrm{A}-\mathrm{B}(63.5: 36.5, v / v) ; 7-9 \mathrm{~min}$, linear change from A-B $(63.5: 36.5, v / v)$ to A-B $(60.5: 39.5, v / v) ; 9-15 \mathrm{~min}$, linear change from A-B $(60.5: 39.5, v / v)$ to A-B $(57.5: 42.5, v / v) ; 15-17$ min, linear change from A-B $(57.5: 42.5, v / v)$ to A-B $(67: 33$, $v / v$ ) and hold for $3 \mathrm{~min}$. The mobile phase flow rate was 1 $\mathrm{mL} / \mathrm{min}$. The chromatogram was recorded at $332 \mathrm{~nm}$. The column temperature was controlled at $30^{\circ} \mathrm{C}$, and the sample injection volume was $40 \mu \mathrm{L}$. Calibration curves were generated by plotting the IS to analyte peak area ratios against analyte concentrations. The intra-day and inter-day precision and accuracy were carried out by quantifying three QC samples $(n=5)$ on the same day and on three consecutive validation days, respectively. The results of the intra-day and inter-day precision were determined by the RSD, and the detected concentration/nominal concentration was calculated to evaluate the accuracy. The recovery was determined as the ratio of the peak area of the precipitated QC samples to that of the samples without precipitation at equivalent concentrations. The storage stability was evaluated by determining QC samples at five replicates stored at $-80^{\circ} \mathrm{C}$ for $30 \mathrm{~d}$.

\section{Data analysis}

The concentration of the perfusion fluid, the effective permeability coefficient $\left(P_{\text {eff }}\right)$ and the absorption rate constant $\left(K_{\mathrm{a}}\right)$ were calculated using the following equations:

$$
\begin{aligned}
& C_{\text {out (corrected) }}=\frac{C_{\text {out }} P R_{\text {in }}}{P R_{\text {out }}} \\
& P_{\text {eff }}=\frac{Q \ln \left[C_{\text {in }} / C_{\text {out (corrected) }}\right]}{2 \pi r L} \\
& K_{\mathrm{a}}=\left[1-\frac{C_{\text {out (corrected) }}}{C_{\text {in }}}\right] Q / \pi r^{2} L
\end{aligned}
$$

Notes: $C_{\text {out (corrected) }}$ is the effluent drug concentration with correction; $C_{\text {out }}$ is the effluent drug concentration without correction; $C_{\text {in }}$ is the influent drug concentration; $P R_{\text {in }}$ is the influent phenol red concentration; $P R_{\text {out }}$ is the effluent phenol red concentration; $Q$ is the perfusate flow rate; $r$ is the radius of intestinal segment and $l$ is the length of intestinal segment.

The reported values are presented as the mean \pm SD. The data were analysed using the Student's $t$-test or a one-way ANOVA. For all tests, $P<0.05$ was considered significant.

\section{Results \\ In vitro Caco- 2 cell model \\ Determination of FTA in HBSS}

Under the current chromatography conditions, all analyses were completed within $3.0 \mathrm{~min}$. The negative mass spectra of 
FTA and IS are shown in Figure 2. The mass spectra of FTA and IS exhibited a protonated molecular ion at $\mathrm{m} / \mathrm{z} 623.8$ and 353.3, respectively. The high collision energy gave the most abundant production at $m / z 161.3$ and 191.2, respectively. Therefore, the precursor to product transition was assigned in the multi-reaction-monitoring (MRM) model as follows: $\mathrm{m} / \mathrm{z}$ $623.1 \rightarrow 161.3$ for FTA and $m / z 353.3 \rightarrow 191.2$ for IS. The MRM chromatograms of FTA and IS are shown in Figure 3. No significant interference from endogenous substances with the analytes or IS was detected. The calibration curve was linear in the range of 5.28 to $132 \mathrm{ng} / \mathrm{mL}$, with a correlation coefficient of $0.992(n=6)$. The regression equation was as follows: $Y=$ $0.0002 X-0.0002$ ( $Y$ : the ratio of peak area, $X$ : the concentration of FTA) when a $10 \mu \mathrm{L}$ sample was used for assay. The precision and accuracy data for the within-run and between-run assays are shown in Table 1 . The results indicate that the present method had good reproducibility with precision less than $10.64 \%$ and excellent accuracy ranging from $93.15 \%$ to $104.25 \%$ at low $(5.28 \mathrm{ng} / \mathrm{mL})$ to high $(264 \mathrm{ng} / \mathrm{mL})$ concentrations. The extraction recoveries of FTA had average values ranging from $56.06 \%$ to $63.26 \%$ at the three QC concentrations (Table 2).
The matrix effect of the blank Caco-2 cell receiver solutions spiked after the sample preparation with 5.28, 26.4, and 132 $\mathrm{ng} / \mathrm{mL}$ of FTA were found to be within the acceptable range (Table 2). The same evaluation was performed on the IS, and no significant peak area differences were observed (Table 2). The results of the short-term stability, freeze/thaw stability, autosampler stability and long-term stability are shown in Table 3. The mean percentages of the deviation of calculated versus theoretical concentrations were less than or equal to $14.97 \%$ for short-term stability, less than or equal to $14.06 \%$ for freeze/thaw stability, less than or equal to $11.93 \%$ for autosampler stability, and less than or equal to $8.32 \%$ for longterm stability, indicating that the analytes were stable during the analytical procedures.

\section{Characteristics of the transepithelial transport of FTA}

The bi-directional permeation of FTA across Caco-2 cell monolayers was examined (Table 4). The permeation of FTA in the apical-to-basolateral direction was similar to that in the basolateral-to-apical direction at a medium concentration, and all of the efflux ratios were less than 1.5 , indicating that the
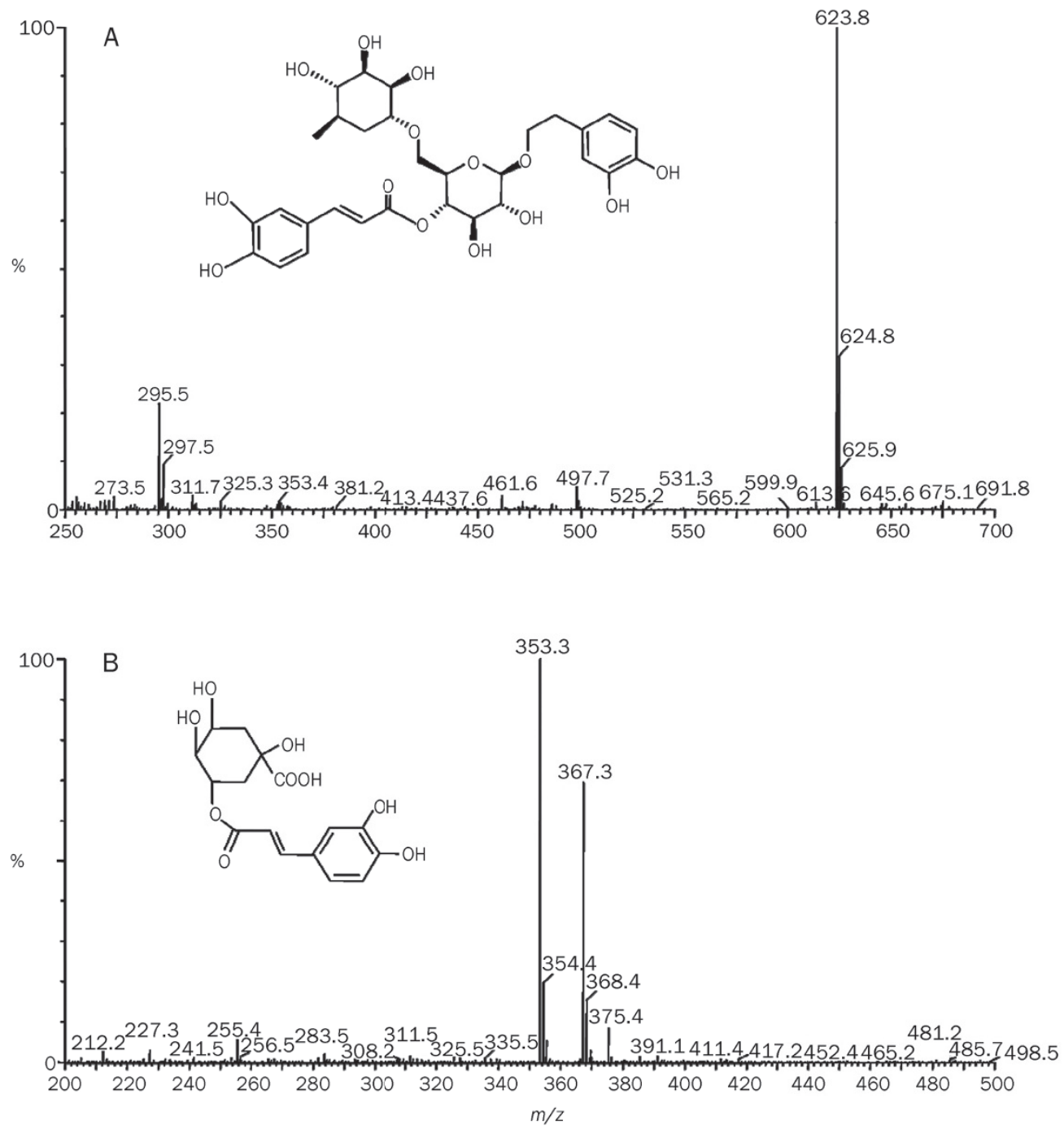

Figure 2. Full-scan product ion spectra of $[\mathrm{M}-\mathrm{H}]$ of $\mathrm{FTA}(\mathrm{A})$ and $\mathrm{CHA}$ (IS) (B) in negative ion mode. 


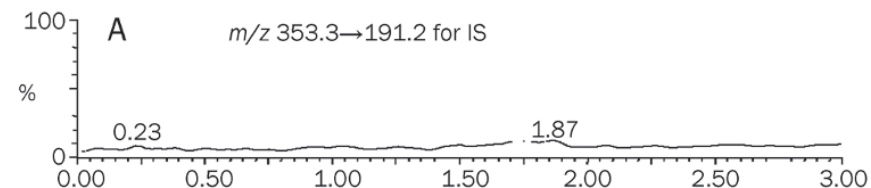

Table 2. Recovery of FTA and CHA (internal standard) in Caco- 2 cells mean \pm standard deviation (SD). $n=3$

\begin{tabular}{lccc}
\hline Sample & $\begin{array}{c}\text { Concentration } \\
(\mathrm{ng} / \mathrm{mL})\end{array}$ & $\begin{array}{c}\text { Recovery } \\
(\%)\end{array}$ & $\begin{array}{c}\text { Matrix effect } \\
(\%)\end{array}$ \\
\hline FTA & 5.28 & $56.06 \pm 5.84$ & $97.0 \pm 2.3$ \\
FTA & 26.4 & $63.26 \pm 9.36$ & $92.3 \pm 1.3$ \\
FTA & 132 & $59.70 \pm 1.41$ & $91.4 \pm 4.7$ \\
IS & 2056 & $88.02 \pm 1.39$ & $92.4 \pm 2.6$ \\
\hline
\end{tabular}
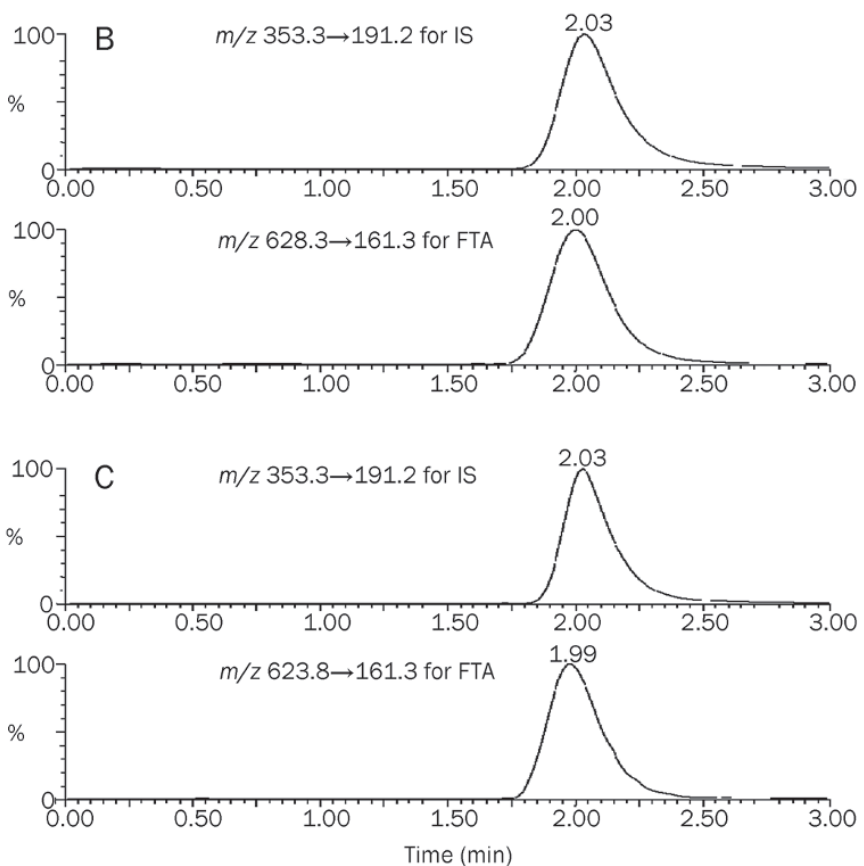

Figure 3. Typical MRM chromatograms of FTA and IS. (A) Blank Caco-2 receiver solution. (B) Blank HBSS spiked with IS and FTA. (C) Samples collected in Caco-2 cell model spiked with IS.

absorption of FTA was not affected by the transport direction.

\section{The distribution of FTA}

After the transport experiments, $>96 \%$ of the apically loaded FTA was retained on the apical side and $>97 \%$ of the basolaterally loaded FTA was retained on the basolateral side when the TEER value was $424 \pm 35 \Omega / \mathrm{cm}^{2}$, suggesting that the permeability of FTA may be restricted by tight junctions (Table 5).

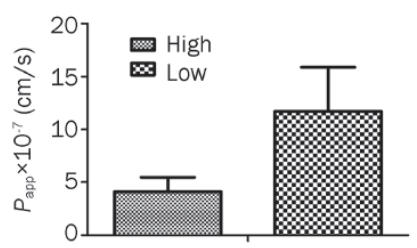

The paracellular transport of FTA across the Caco-2 cell monolayers

Caco-2 cell monolayers exhibiting different TEER values were prepared by treatment with cytochalasin D. The apical-tobasolateral transport of FTA was then characterised using the monolayers. As illustrated in Figure 4, the $P_{\text {app }}$-values of FTA were inversely correlated with the TER, suggesting that they permeated across Caco- 2 cell monolayers via the paracellular pathways. This finding also suggests that the intestinal absorption of FTA is restricted when the epithelial tight junction was tight enough. As shown in Figure 5, the $P_{\text {app }}$ values also increased significantly $(P<0.01)$ to $779 \%$ $(31.87 \pm 5.92) \times 10^{-7} \mathrm{~cm} / \mathrm{s}, 1126 \%(46.07 \pm 2.92) \times 10^{-7} \mathrm{~cm} / \mathrm{s}$ and $1540 \%(62.98 \pm 6.76) \times 10^{-7} \mathrm{~cm} / \mathrm{s}$ following a prior 40 -min exposure of the Caco-2 cells to 10, 20 and $30 \mu \mathrm{mol} / \mathrm{L}$ of the paracellular permeability enhancer sodium caprate, suggesting that FTA permeates via the paracellular pathways. the $P_{\text {app }}$-values increased significantly $(P<0.01)$ to $528 \%(21.60 \pm 3.88) \times 10^{-7} \mathrm{~cm} / \mathrm{s}$, $934 \%(38.22 \pm 7.10) \times 10^{-7} \mathrm{~cm} / \mathrm{s}$ and $1538 \%(62.91 \pm 4.82) \times 10^{-7} \mathrm{~cm} / \mathrm{s}$ following a prior $40-\mathrm{min}$ exposure of the Caco-2 cells to 10, 20 , and $30 \mu \mathrm{mol} / \mathrm{L}$ of the paracellular permeability enhancer EDTA.

Figure 4. Correlation between TEER and the $P_{\text {app }}$-values. TEER values are indicated as follows: high, 800 , and low, $383 \Omega / \mathrm{cm}^{2}$. Each point is the mean $\pm S D$ of three experiments.

Table 1. Intra- and inter-day accuracy and precision of FTA assay in Caco-2 cells.

\begin{tabular}{|c|c|c|c|c|c|c|}
\hline \multirow[b]{2}{*}{$\begin{array}{l}\text { Concentration } \\
\qquad(\mathrm{ng} / \mathrm{mL})\end{array}$} & \multicolumn{3}{|c|}{ Intra-day (overall mean, $n=5$ ) } & \multicolumn{3}{|c|}{ Inter-day (overall mean, $n=15$ ) } \\
\hline & $\begin{array}{l}\text { Concentration found } \\
\qquad(\mathrm{ng} / \mathrm{mL})\end{array}$ & $\begin{array}{c}\text { Accuracy } \\
(\%)\end{array}$ & $\begin{array}{l}\text { CV } \\
(\%)\end{array}$ & $\begin{array}{l}\text { Concentration found } \\
\qquad(\mathrm{ng} / \mathrm{mL})\end{array}$ & $\begin{array}{c}\text { Accuracy } \\
(\%)\end{array}$ & $\begin{array}{l}\text { CV } \\
(\%)\end{array}$ \\
\hline 5.28 & 5.50 & 104.25 & 9.83 & 5.15 & 97.59 & 11.40 \\
\hline 26.4 & 25.05 & 94.89 & 10.99 & 25.73 & 97.45 & 6.40 \\
\hline 132 & 126.52 & 95.85 & 10.64 & 122.95 & 93.15 & 6.08 \\
\hline
\end{tabular}


Table 3. Stability of FTA in Caco- 2 cells. $n=3$. Mean \pm SD.

\begin{tabular}{|c|c|c|c|}
\hline & \multicolumn{3}{|c|}{ FTA nominal concentration (ng/mL) } \\
\hline & 5.28 & 26.4 & 132 \\
\hline Room temperature (4 h) Measured concentration (ng/mL) & $5.78 \pm 0.79$ & $24.62 \pm 2.32$ & $125.10 \pm 10.81$ \\
\hline Accuracy $(\%)$ & $109.52 \pm 14.97$ & $93.27 \pm 8.79$ & $94.77 \pm 8.19$ \\
\hline Three freeze/thaw cycles Measured concentration (ng/mL) & $5.46 \pm 0.80$ & $26.30 \pm 3.10$ & $124.99 \pm 10.93$ \\
\hline Accuracy $(\%)$ & $103.40 \pm 14.06$ & $98.59 \pm 11.73$ & $94.69 \pm 8.28$ \\
\hline Accuracy $(\%)$ & $102.92 \pm 11.93$ & $92.81 \pm 4.97$ & $93.43 \pm 8.81$ \\
\hline Stored at $-20^{\circ} \mathrm{C}$ for 4 weeks Measured concentration $(\mathrm{ng} / \mathrm{mL})$ & $5.09 \pm 0.19$ & $24.96 \pm 2.20$ & $122.78 \pm 8.01$ \\
\hline Accuracy $(\%)$ & $96.34 \pm 3.57$ & $94.54 \pm 8.32$ & $93.01 \pm 6.07$ \\
\hline
\end{tabular}

Table 4. Transport parameters of different concentrations of FTA in Caco- 2 cells. $n=3$. Mean $\pm S D$.

\begin{tabular}{cccc}
\hline $\begin{array}{c}\text { Concentration } \\
(\mu \mathrm{g} / \mathrm{mL})\end{array}$ & AP-BL & $P_{\mathrm{app}} \times 10^{-7}(\mathrm{~cm} / \mathrm{s})$ & $P_{\mathrm{BA}} / P_{\mathrm{AB}}$ \\
\hline 2.6 & $3.99 \pm 0.23$ & $3.99 \pm 0.69$ & 1.00 \\
5.2 & $4.15 \pm 1.20$ & $3.52 \pm 0.73$ & 0.85 \\
10.4 & $4.09 \pm 1.37$ & $3.89 \pm 0.87$ & 0.95 \\
\hline
\end{tabular}

Table 5. Distribution of FTA after transepithelial transport experiments.

\begin{tabular}{lrcc}
\hline $\begin{array}{l}\text { Transport } \\
\text { direction }\end{array}$ & Apical side & $\begin{array}{c}\text { \% Compound recovered from } \\
\text { Basolateral side }\end{array}$ & Cells \\
\hline AP-BL & $96.84 \pm 0.55$ & $3.10 \pm 0.56$ & $0.02 \pm 0.01$ \\
BL-AP & $2.51 \pm 0.12$ & $97.44 \pm 0.12$ & $0.04 \pm 0.02$ \\
\hline
\end{tabular}

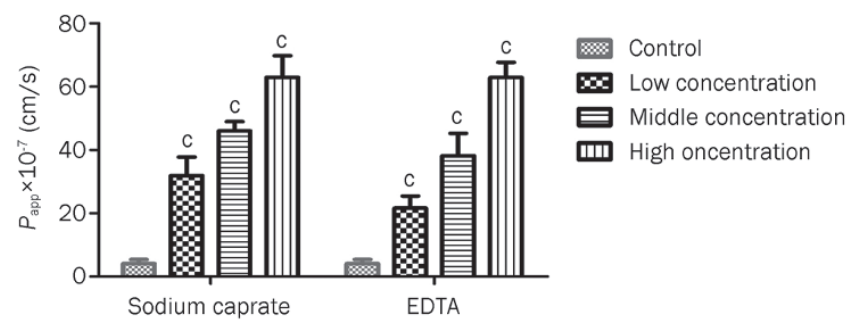

Figure 5. Effects of paracellular permeability enhancers at different concentrations on absorption parameters of FTA in Caco- 2 cell model. Results are expressed as the mean $\pm S D$ of at least four experiments. ${ }^{c} P<0.01$ compared with the control group. Low, Middle, High: 10, 20, 30 $\mu \mathrm{mol} / \mathrm{L}$ for both sodium caprate and EDTA.

\section{The concentration dependence of FTA}

As shown in Table 4, there were no significant differences in permeability calculated by different concentrations ranging from $2.6 \mu \mathrm{g} / \mathrm{mL}$ to $10.4 \mu \mathrm{g} / \mathrm{mL}$, suggesting that passive diffusion might be involved. This result is in good agreement with the distribution study and the results shown in Figure 4 and 5, showing that FTA was mainly permeated via paracellular diffusion. LY, a marker compound for paracellular transport, also showed this trend ${ }^{[24]}$.

The influence of different inhibitor concentrations on the transport parameters of FTA in the Caco-2 cell model

Figure 6 summarises the permeability coefficients of FTA in the absence and presence of inhibitors. Our statistical analysis revealed that exposure to VER (50 and $100 \mu \mathrm{mol} / \mathrm{L}$ ), CSA (5 $\mu \mathrm{mol} / \mathrm{L})$ and MK571 $(50 \mu \mathrm{mol} / \mathrm{L})$ did not increase the $P_{\text {app }}-$ values significantly. However, the $P_{\text {app }}$-values increased significantly $(P<0.05)$ to $184 \%(7.52 \pm 0.35) \times 10^{-7} \mathrm{~cm} / \mathrm{s}$ in the presence of $150 \mu \mathrm{mol} / \mathrm{L}$ of VER. The $P_{\text {app }}$-values increased significantly $(P<0.05)$ to $152 \%(6.23 \pm 1.47) \times 10^{-7} \mathrm{~cm} / \mathrm{s}$ and $298 \%$ $(12.20 \pm 3.46) \times 10^{-7} \mathrm{~cm} / \mathrm{s}$ in the presence of 10 and $15 \mu \mathrm{mol} / \mathrm{L}$ of CSA, and the $P_{\text {app }}$-values increased significantly $(P<0.05)$ to $220 \%(9.00 \pm 7.60) \times 10^{-7} \mathrm{~cm} / \mathrm{s}$ and $249 \%(10.20 \pm 4.40) \times 10^{-7} \mathrm{~cm} / \mathrm{s}$ in the presence of 100 and $150 \mu \mathrm{mol} / \mathrm{L}$ of MK571. These results indicate that the permeability of FTA is enhanced as the concentrations of VER, CSA, MK571 are increased, exhibiting a clear concentration-dependent effect. However, the $P_{\text {app }}{ }^{-}$ values decreased gradually in the presence of $40 \mu \mathrm{mol} / \mathrm{L}$ of DFS and INDO. In addition, the $P_{\text {app }}$-values in the presence of

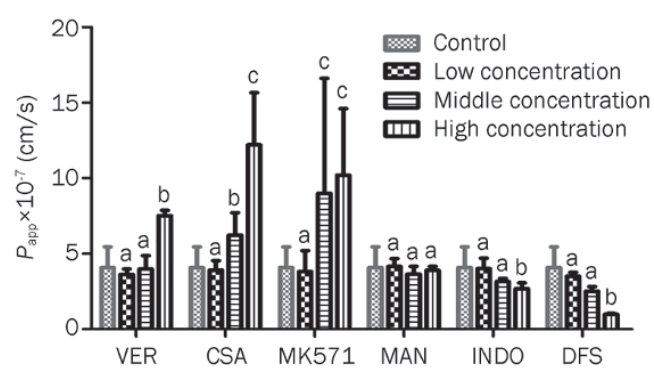

Figure 6. Effects of inhibitors of different concentrations on absorption parameters of FTA in Caco- 2 cell model. Results are expressed as the mean \pm SD of at least four experiments. ${ }^{a} P>0.05,{ }^{b} P<0.05,{ }^{c} P<0.01$ compared with the control group. VER: 50, 100, $150 \mu \mathrm{mol} / \mathrm{L}$; CSA: 5, 10,

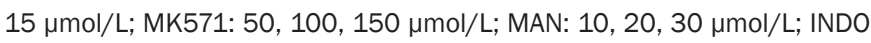
and DFS: 10, 20, $40 \mu \mathrm{mol} / \mathrm{L}$. 
10,20 , and $30 \mu \mathrm{mol} / \mathrm{L}$ of mannitol did not change significantly compared to the control group. Together, these results indicate that FTA absorption might be influenced by efflux transporters (P-gp, MRPs) and uptake transporters (OATP).

\section{The single-pass intestinal perfusion in situ model The determination of phenol red}

A linear relationship between the phenol red concentration in the range of 10 to $50 \mathrm{mg} / \mathrm{L}$ and the absorbance was found. The calibration was $A=0.0098 C-0.0038$, (A: absorbance, $C$ : the concentration of phenol red), $r=0.9999(n=6)$. The average recovery was $100.03 \%$, and the precision (RSD) was less than $1.18 \%$. These results indicate that this method is suitable for the determination of phenol red in the intestinal perfusion fluid.

\section{The determination of FTA in the intestinal perfusion fluid}

No interfering peak was observed in the blank intestinal perfusion fluid under the assay conditions. The retention time was approximately $14.7 \mathrm{~min}$ for FTA and $5.8 \mathrm{~min}$ for IS. The calibration curve was linear in the range of $0.615-12.3 \mu \mathrm{g} / \mathrm{mL}$ with a correlation coefficient of $0.9985(n=7)$. The regression equation was as follows: $Y=0.023 X+0.0006(Y$ : the concentration of FTA, X: the ratio of peak area) when $100 \mu \mathrm{L}$ of perfusion fluid was used for assay. The precision and accuracy data for the within-run and between-run assays are shown in Table 6. The results indicate that the developed HPLC method had good reproducibility with precision less than $4.61 \%$ and excellent accuracy ranging from $88.65 \%$ to $110.83 \%$ at low $(1.23$ $\mu \mathrm{g} / \mathrm{mL})$ to high $(11.07 \mu \mathrm{g} / \mathrm{mL})$ concentrations. The extraction recoveries of FTA had average values ranging from $96.86 \%$ to $102.98 \%$ at the three QC concentrations (Table 6). The stability results (data not shown) showed that the concentrations of FTA were between $96.8 \%$ and $108.5 \%$ of the initial values, indicating that the analytes were stable in the intestinal perfu- sion fluid for at least $30 \mathrm{~d}$ storage at $-80^{\circ} \mathrm{C}$.

\section{The absorption parameters of different concentrations in different segments of rat intestine}

As shown in Table 7 , the $K_{\mathrm{a}}$ and $P_{\text {eff }}$-values changed little $(P>0.05$, ANOVA) in the presence of $2.6,5.2$, and $10.4 \mu \mathrm{g} / \mathrm{mL}$ of FTA after perfusion via the duodenum, jejunum and ileum, indicating that the absorption of FTA might be primarily through passive diffusion. In addition, it was shown that the $K_{\mathrm{a}}$ and $P_{\text {eff }}$-values in the duodenum were slightly higher compared to the jejunum and ileum, but this difference was not significant (Table 7). This indicates that the predominant absorption site might be in the upper part of small intestine.

\section{The influence of different concentrations of inhibitors and paracellular permeability enhancers on the absorption para- meters of FTA}

As shown in Figure 7, the addition of VER induced the greatest increase in the $P_{\text {eff }}$-values at a relatively low concentration $(50 \mu \mathrm{mol} / \mathrm{L})$ in the duodenum, a medium concentration (100 $\mu \mathrm{mol} / \mathrm{L})$ in the jejunum and a high concentration $(150 \mu \mathrm{mol} / \mathrm{L})$ in the ileum. CSA at low $(2 \mu \mathrm{g} / \mathrm{mL})$, medium $(4 \mu \mathrm{g} / \mathrm{mL})$ and high $(8 \mu \mathrm{g} / \mathrm{mL})$ concentrations produced a significant, dosedependent increase in the $P_{\text {eff }}$-value, and the duodenum, jejunum and ileum showed the same trend in $P_{\text {eff-values when }}$ CSA was added. The treatment with a high concentration of CSA led to a significant increase in the $P_{\text {eff }}$-value compared to the control $(P<0.05)$, and the $P_{\text {eff }}$-value in the duodenum group when CSA was added was higher than that of the jejunum and ileum groups. Both sodium caprate and EDTA at the same low $(5 \mu \mathrm{g} / \mathrm{mL})$, medium $(10 \mu \mathrm{g} / \mathrm{mL})$ and high $(15$ $\mu \mathrm{g} / \mathrm{mL}$ ) concentrations caused a significant, concentrationdependent increase in the $P_{\text {eff-value compared to the control }}$ group $(P<0.05)$. Treatment with sodium caprate and EDTA at the same high concentrations had the highest $P_{\text {eff-value. These }}$

Table 6. Within-run and between-run precision and accuracy, and extraction recovery of the method for determination of FTA in rat intestinal perfusate.

\begin{tabular}{|c|c|c|c|c|c|c|}
\hline \multirow{2}{*}{$\begin{array}{l}\text { Concentration } \\
\qquad(\mu \mathrm{g} / \mathrm{mL})\end{array}$} & \multicolumn{2}{|c|}{ Within-run $(n=5)$} & \multicolumn{2}{|c|}{ Between-run ( $n=5$, three runs) } & \multicolumn{2}{|c|}{ Recovery (\%) } \\
\hline & Precision (RSD\%) & Accuracy (\%) & Precision (RSD\%) & Accuracy (\%) & Mean & RSD\% \\
\hline 4.92 & 0.29 & 95.44 & 0.99 & 110.83 & 96.86 & 0.04 \\
\hline 11.07 & 0.12 & 98.06 & 2.45 & 106.92 & 101.27 & 1.12 \\
\hline
\end{tabular}

Table 7. Absorption parameters of three concentrations of FTA in different segments of rat intestine. $n=5$. Mean \pm SD.

\begin{tabular}{|c|c|c|c|c|}
\hline Concentration & Parameter & Duodenum & Jejunum & Ileum \\
\hline \multirow[t]{2}{*}{ Low $(2.6 \mu \mathrm{g} / \mathrm{mL})$} & $P_{\mathrm{eff}} \times 10^{-6}(\mathrm{~cm} / \mathrm{s})$ & $5.485 \pm 2.621$ & $3.811 \pm 3.036$ & $3.008 \pm 2.249$ \\
\hline & $K_{\mathrm{a}} \times 10^{-5}\left(\mathrm{~min}^{-1}\right)$ & $5.707 \pm 2.410$ & $3.907 \pm 2.419$ & $3.115 \pm 2.325$ \\
\hline \multirow[t]{2}{*}{ Middle $(5.2 \mu g / m L)$} & $P_{\mathrm{eff}} \times 10^{-6}(\mathrm{~cm} / \mathrm{s})$ & $4.550 \pm 0.417$ & $4.433 \pm 2.704$ & $4.306 \pm 2.107$ \\
\hline & $K_{a} \times 10^{-5}\left(\min ^{-1}\right)$ & $5.671 \pm 0.516$ & $5.554 \pm 1.534$ & $5.370 \pm 0.149$ \\
\hline 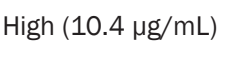 & $P_{\text {eff }} \times 10^{-6}(\mathrm{~cm} / \mathrm{s})$ & $5.494 \pm 3.883$ & $4.682 \pm 2.971$ & $3.191 \pm 2.519$ \\
\hline
\end{tabular}


A Duodenum
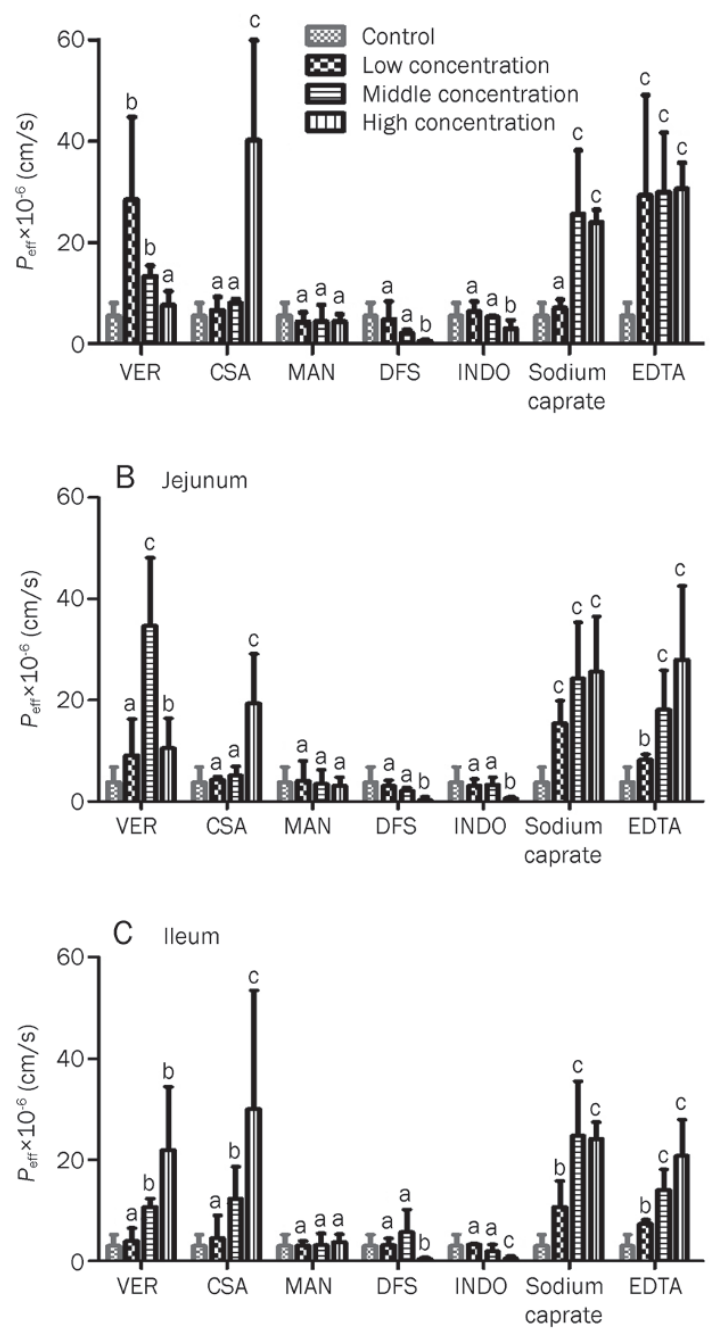

Figure 7. Effects of inhibitors at different concentrations and paracellular permeability enhancers on absorption parameters of FTA in rat single pass intestinal perfusion via duodenum, jejunum and ileum in situ model. Results are expressed as the mean $\pm S D$ of at least four experiments. ${ }^{\mathrm{a}} P>0.05,{ }^{\mathrm{b}} P<0.05,{ }^{\mathrm{c}} P<0.01$ compared with the control group. VER: 50 , 100, 150 mmol/L; CSA: 5, 10, $15 \mu \mathrm{mol} / \mathrm{L} ; \mathrm{MK571:} \mathrm{50,} \mathrm{100,} 150 \mu \mathrm{mol} / \mathrm{L}$; MAN: 10, 20, $30 \mu \mathrm{mol} / \mathrm{L}$; INDO and DFS: 10, 20, 40 mmol/L.

results show that the permeability of FTA is enhanced as the concentrations of EDTA and sodium caprate increase, exhibiting a clear concentration-dependent effect. However, DFS and INDO at the same low $(25 \mu \mathrm{g} / \mathrm{mL})$, medium $(50 \mu \mathrm{g} / \mathrm{mL})$ and high $(100 \mu \mathrm{g} / \mathrm{mL})$ concentrations resulted in a significant, dose-dependent decrease in the $P_{\text {eff-value. Treatment }}$ with DFS and INDO at the same high concentration led to a significant decrease in the $P_{\text {eff }}$-value compared to the control $(P<0.05, P<0.01)$ in the duodenum, jejunum and ileum. The $P_{\text {eff }}$-value in the duodenum group when DFS and INDO were added showed less of a decrease than that of the jejunum and ileum groups. In addition, there was no significant difference between treatments with MAN at low $(5 \mathrm{mg} / \mathrm{mL})$, medium (10 $\mathrm{mg} / \mathrm{mL})$ and high $(15 \mathrm{mg} / \mathrm{mL})$ concentrations and the control in the duodenum, jejunum or ileum groups. Together, these results indicate that the absorption of FTA may be influenced by paracellular permeability enhancers, efflux transporters (P-gp, MRPs) and uptake transporters (OATP), which is in accordance with the results from the Caco-2 cell model.

\section{Discussion}

For drugs to be therapeutically effective, they have to possess favourable characteristics to cross the biological membranes into systemic circulation and reach the site of action. Drugs cross membranes via transcellular or paracellular routes. The transcellular pathway involves the passage of the drug across the cells, while the paracellular pathway refers to the passage of drugs between adjacent cells. The major pathway for the absorption or transport of a drug depends on its physicochemical characteristics as well as the membrane features. Salama et al, 2006 ${ }^{[25]}$ reported that lipophilic drugs cross biological membranes transcellularly, while hydrophilic drugs cross the membrane paracellularly. The results of the distribution study (Table 5) and the permeability study (Figure 5) support the conclusion that the absorption of FTA mainly involved paracellular diffusion owning to its high hydrophilicity.

Based on the single-pass intestinal perfusion in situ model, VER was reported as an inhibitor of P-gp and the CYP3A enzyme. The finding that the addition of VER induced the greatest increase in the $P_{\text {eff-values at a relatively low concen- }}$ tration $(50 \mu \mathrm{mol} / \mathrm{L})$ in duodenum, a medium concentration $(100 \mu \mathrm{mol} / \mathrm{L})$ in the jejunum and a high concentration (150 $\mu \mathrm{mol} / \mathrm{L})$ in the ileum while exhibiting no concentration-dependent effect might be explained by the fact that P-gp expression was increased gradually, but CYP3A enzyme expression showed the opposite pattern. As shown in Table 7, the $K_{\mathrm{a}}$ value of the duodenum was slightly higher than the jejunum and ileum, which is consistent with this expression pattern. Furthermore, it was also reported that CSA inhibits MRPs and OATP, while DFS and INDO inhibit OATP. Our finding that the $P_{\text {eff-value in the duodenum group treated with CSA was }}$ higher than that of the jejunum and ileum groups while the $P_{\text {eff }}$-value in the duodenum group treated with DFS and INDO was decreased less than that of the jejunum and ileum groups are consistent with the report by Kusuhara et al, 2003 ${ }^{[19]}$ showing that the uptake transporter (OATP) is expressed mainly in the jejunum and ileum. Ma et al, $2007^{[18]}$ reported that MAN was an inhibitor of SGLT1. As shown in Figure 7, there was no significant difference between the MAN and control treatments in the duodenum, jejunum or ileum groups, indicating that the absorption of FTA was not influenced by intake transport (SGLT1). The mechanism of the absorption enhancing effect of sodium caprate was proposed to be an effect on tight junctions (TJs) through PLC-dependent IP3/DAG pathways. The $P_{\text {eff }}$-value of FTA was enhanced as the concentration of sodium caprate was increased, exhibiting a clear concentration-dependent effect. Zornoza et al, 2004 ${ }^{[26]}$ reported that the absorption enhancing effect of sodium caprate for acamprosate showed a clear concentration-dependent effect. Therefore, our present results are consistent with the previous report. In 
addition, calcium depletion by a chelating agent (EDTA) was also reported to increase paracellular permeability ${ }^{[21]}$, and the $P_{\text {eff }}$-value of FTA was increased as the concentration of EDTA was increased, further illustrating that the absorption of FTA involved paracellular transport.

In the Caco- 2 cell model in vitro, the $P_{\text {app }}$-value of FTA was enhanced as the concentrations of VER, CSA, and MK571 were increased, exhibiting a clear concentration-dependent effect. However, the $P_{\text {app }}$-values decreased significantly as DFS and INDO were added. In addition, the $P_{\text {app }}$-values increased significantly in the presence of paracellular permeability enhancers (EDTA and sodium caprate). These results indicate that the absorption of FTA primarily involves the paracellular transport route, and P-gp, MRPs and OATP might participate

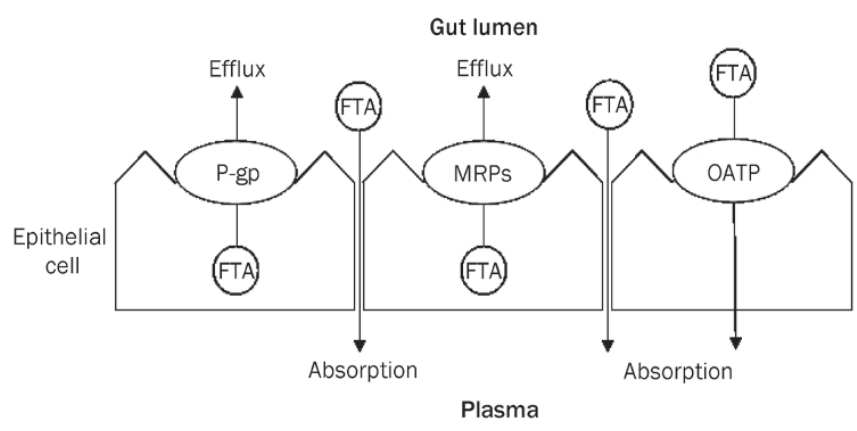

Figure 8. Possible routes for absorption of FTA.

in the absorption of FTA in the intestine as shown in Figure 8.

As shown in Table 4, the efflux ratio was $<1.5$ over the range of 2.6-10.4 $\mu \mathrm{g} / \mathrm{mL}$ of FTA in the bi-directional transport studies, suggesting that the absorption of FTA is not influenced by efflux/uptake transporters ${ }^{[27]}$. However, our present study showed that the absorption of FTA was affected by the inhibitor of P-gp (VER) and the inhibitor of MRPs (CSA, MK571), as illustrated in Figure 6 and 7, which suggests that efflux transporters might influence the absorption of FTA little or that uptake transporters might participate in the absorption of FTA to counteract the effect of efflux transporters ${ }^{[28]}$. Evidence supporting this hypothesis is shown in Figure 6 and 7. The $P_{\text {app }}{ }^{-}$ value and $P_{\text {eff }}$-value of FTA were decreased significantly by the addition of OATP inhibitors (DFS, INDO) in both the in vitro Caco-2 cell model and the in situ single-pass intestinal perfusion model. Therefore, the absorption of FTA may involve not only efflux (P-gp, MRPs) but also uptake (OATP) transporters.

As shown in Tables 4 and 7, FTA was transported at approximately a 10 -fold slower rate in the Caco-2 monolayers than in the rat small intestine. Plausible explanations for the different values were that the permeability of the paracellular pathway and the absorptive surface areas of the two models were different ${ }^{[29,30]}$. In addition, the differences in metabolism between in situ single-pass intestinal perfusion and in vitro Caco-2 cell models resulting from intestinal bacteria and enzymes ${ }^{[31]}$ could also explain the differences in the absorption parameters.

According to Table 4, $P_{\text {app (AP } \rightarrow \text { BL) }}$ was less than $2 \times 10^{-6} \mathrm{~cm} / \mathrm{s}^{[32]}$ due to the efflux (P-gp, MRPs) function and high hydrophilicity paired with low lipid solubility, indicating that FTA might belonged to the class III of the biopharmaceutical classification system $(\mathrm{BCS})^{[33]}$. The permeation through biomembranes is a rate-limiting process that results in low oral BA. It was reported that chitosan and its derivatives ${ }^{[34]}$, sodium caprate ${ }^{[35]}$, $L_{\text {-arginine }}{ }^{[36]}$ and glycyrrhetinic acid, an active ingredient in Radix Liquiritiae ${ }^{[37]}$, could modulate TJs to enhance paracellular transport. Pluronic block copolymers, like Pluronic F68, could inhibit P-gp/CYP3A4 $4^{[38]}$. In addition, prodrug designations, like peptide prodrug modifications, could also shield FTA from the efflux pump ${ }^{[39]}$. Therefore, investigations into improving the permeability of FTA using pharmaceutical methods based on the above research and evaluating the toxicity of pharmaceutical excipients (functional excipients or additives) are required to improve the oral BA of FTA.

\section{Acknowledgements}

The present study was supported financially by the "Qing Lan" Project from Jiangsu Provincial Technology Innovation Team Support Scheme, the priority Academic Program Development of Jiangsu Higher Education Institution (No ysxk2010) and 2012 program sponsored for scientific innovation research of college graduate in Jiangsu province (623).

\section{Author contribution}

Wei ZHOU designed experiments, performed research, analysed data, and wrote the paper. Liu-qing DI performed the research. Juan WANG, Jin-jun SHAN, Shi-jia LIU, Wen-zheng $\mathrm{JU}$, and Bao-chang CAI helped write the paper.

\section{References}

1 Liu Y, Hu M. Absorption and metabolism of flavonoids in the Caco-2 cell culture model and a perfused rat intestinal model. Drug Metab Dispos 2002; 30: 370-7.

2 Helen Chan O, Sinz MW, Stewart BH. Multiple-model evaluation of absorption of a tachykinin receptor antagonist. Adv Drug Deliv Rev 1997; 23: 121-31.

3 Artursson P, Palm K, Luthman K. Caco-2 monolayers in experimental and the oretical predictions of drug transport. Adv Drug Deliv Rev 2001; 46: $27-43$.

4 Hidalgo IJ, Li J. Carrier-mediated transport and efflux mechanisms in Caco-2 cells. Adv Drug Deliv Rev 1996; 22: 53-66.

5 Wang XD, Meng MX, Gao LB, Liu T, Xu Q, Zeng S. Permeation of astilbin and taxifolin in Caco-2 cell and their effects on the P-gp. Int J Pharm 2009; 378: 1-8.

6 Yu LS, Zeng S. Transport characteristics of zolmitriptan in a human intestinal epithelial cell line Caco-2. J Pharm Pharmacol 2007; 59: 655-60.

7 Painc MF, Fisher MB. Immunochemical identification of UGT isoforms in human small bowel and in Caco-2 cell monolayers. Biochem Biophys Res Commun 2000; 273: 1053-7.

8 Bohets $\mathrm{H}$, Annaert P, Mannens G, Van Beijsterveldt L, Anciaux $\mathrm{K}$, Verboven $\mathrm{P}$, et al. Strategies for absorption screening in drug discovery and development. Curr Topic Med Chem 2001; 1: 367-83.

9 Zuo Z, Zhang L, Zhou LM, Chang Q, Chow M. Intestinal absorption of hawthorn flavonoids - in vitro, in situ and in vivo correlations. Life Sci 2006; 79: 2455-62. 
10 State Pharmacopoeia Committee, 2010. Chinese Pharmacopoeia, vol.1, Beijing: Chemical Industry Press; 2010. p159.

11 Zhang LW. Extraction method, and biological activities of forsythiaside. Taiyuan: Shanxi University; 2002.

12 Wang GN, Pan RL, Liao YH, Chen Y, Tang JT, Chang Q. An LC-MS/MS method for determination of forsythiaside in rat plasma and application to a pharmacokinetic study. J Chromatogr B 2010; 878: 102-6.

13 Lu WG, Wang LL, Chen TT, Yu LF, Yang YJ, inventors; Shang ZX. Patent Agent LTD, assignee. One forsythiaside combination. China patent CN101919869A. 2010 Dec 22.

14 Zornoza T, Cano-Cebrian MJ, Nalda-Molina R, Guerri C, Granero L, Polache A. Assessment and modulation of acamprosate intestinal absorption: comparative studies using in situ, in vitro (CACO-2 cell monolayers) and in vivo models. Eur J Pharm Sci 2004; 22: 347-56.

15 Du Q, Di LQ, Shan JJ, Liu TS, Zhang XZ. Intestinal absorption of daphnetin by rats single pass perfusion in situ. Yao Xue Xue Bao 2009; 44: 922-6.

16 Walgren RA, Karnaky KJ Jr, Lindenmayer GE, Walle T. Efflux of dietary flavonoid quercetin 4'-beta-glucoside across human intestinal Caco-2 cell monolayers by apical multidrug resistance-associated protein- 2 . J Pharmacol Exp Ther 2000; 294: 830-6.

17 Wolffram S, Block M, Ader P. Quercetin-3-glucoside is transported by the glucose carrier SGLT1 across the brush border membrane of rat small intestine. J Nutr 2002; 132: 630-5.

18 Ma G. Study on absorptive mechanism and modulation of Hawthorn Leaves Flavonoids [D]. Chengdu: Sichuan University; 2007.

19 Kusuhara H, He Z, Nagata Y, Nozaki Y, Ito T, Masuda H, et al. Expression and functional involvement of organic anion transporting polypeptide subtype 3 (SIc21a7) in rat choroid plexus. Pharm Res 2003; 20: $720-7$.

20 Wang L. Preparation of feisuoweima double-layer sustained release tablets and studies on fexofenadine hydrochloride intestinal absorption in rat in vitro $[D]$. Shengyang: Shengyang Pharmaceutical University; 2003.

21 Deli MA. Potential use of tight junction modulators to reversibly open membranous barriers and improve drug delivery. Biochim Biophys Acta 2009; 1788: 892-910.

22 Lindmark T, Kimura Y, Artursson P. Absorption enhancement through intracellular regulation of tight junction permeability by medium chain fatty acids in Caco-2 cells. J Pharmacol Exp Ther 1998; 284: 362-9.

23 Zhou W, Di LQ, Shan JJ, Bi XL, Chen LT, Wang LC. Intestinal absorption of forsythoside $\mathrm{A}$ in different compositions of Shuang-Huang-Lian. Fitoterapia 2011; 82: 375-82.

24 Konishi Y, Hagiwara K, Shimizu M. Transepithelial transport of fluorescein in Caco-2 cell monolayers and its use in in vitro evaluation of phenolic acids availability. Biosci Biotech Biochem 2002; 66: 2449-57.

25 Salama NN, Eddington ND, Fasano A. Tight junction modulation and its relationship to drug delivery. Adv Drug Delivery Rev 2006; 58 : 15-28.

26 Zornoza T, Cano-Cebrián MJ, Nalda-Molina R, Guerri C, Granero L, Polache A. Assessment and modulation of acamprosate intestinal absorption: comparative studies using in situ, in vitro (Caco-2 cell monolayers) and in vivo models. Eur J Pharm Sci 2004; 24: 347-56.

27 Ping QN, editors. Gastrointestinal transport and pharmaceutical designation of ingredients in Chinese medicine. Beijing: Chemical Industry Press; 2010. p 257.

28 Rodrigues AC, Curi R, Genvigir FD, Hirata MH, Hirata RD. The expression of efflux and uptake transporters are regulated by statins in Caco-2 and HepG2 cells. Acta Pharmacol Sin 2009; 30: 956-64.

29 Pinto M, Robine-Leon S, Appay MD. Enterocyte-like differentiation and polarization of the human colon carcmoma cell line Caco-2 in culture. Biol Cell 1983; 47: 323-30.

30 Artursson P. Epithelial transport of drugs I. A model for studying the transport of drugs ( $\beta$-blocking agents) over an intestinal epithelial cell line (Caco-2). J Pharm Sci 1990; 79: 476-82.

31 Zhou W, Di LQ, Bi XL, Chen LT, Du Q. Intestinal absorption of forsythoside A by rat circulation in situ. Yao Xua Xue Bao 2010; 45: 1373-8.

32 Rinaki E, Dokoumentzidis A, Valsami G, Macheras P. Identification of biowaivers among class II drugs: theoretical justification and practical examples. Pharm Res 2004; 21: 1567-72.

33 Sachan NK, Bhattacharya A, Pushkar S, Mishra A. Biopharmaceutical classification system: A strategic tool for oral drug delivery technology. Asian J Pharm 2009; 3: 76-81.

34 Gao Y, He L, Katsumi H, Sakane T, Fujita T, Yamamoto A. Improvement of intestinal absorption of insulin and water-soluble macromolecular compounds by chitosan oligomers in rats. Int J Pharm 2008; 359: 70-8.

35 Lindmark T, Kimura Y, Artursson R. Absorption enhancement through intracellular regulation of tight junction permeability by medium chain fatty acids in Caco-2 cells. J Pharmacol Exp Ther 1998; 284: 362-9.

36 Motlekar NA, Srivenugopal KS, Wachtel MS, Youan BC. Modulation of gastrointestinal permeability of low-molecular-weight heparin by L-arginine: in-vivo and in-vitro evaluation. J Pharm Pharmacol 2006; 58: 591-8.

37 Motlekar NA, Srivenugopal KS, Wachtel MS, Youan BB. Evaluation of the oral bioavailability of low molecular weight heparin formulated with glycyrrhetinic acid as permeation enhancer. Drug Develop Res 2006; 67: 166-74.

38 Huang JG, Si LQ, Jiang LL, Fan Z, Qiu J, Li G. Effect of pluronic F68 block copolymer on P-glycoprotein transport and CYP3A4 metabolism. Int J Pharm 2008; 356: 351-3.

39 Jain R, Duvvuri S, Kansara V, Mandava NK, Mitra AK. Intestinal absorption of novel-dipeptide prodrugs of saquinavir in rats. Int $J$ Pharm 2007; 336: 233-40. 